\title{
Development and characterization of silicone/phosphorus modified epoxy materials and their application as anticorrosion and antifouling coatings
}

\author{
S. Ananda Kumar ${ }^{\mathrm{a}, *}$, T. Balakrishnan ${ }^{\mathrm{a}}$, M. Alagar ${ }^{\mathrm{b}}$, Z. Denchev $^{\mathrm{c}}$ \\ ${ }^{a}$ Department of Physical Chemistry, University of Madras, Chennai 600 025, India \\ ${ }^{\mathrm{b}}$ Department of Chemical Engineering, Anna University, Chennai 600 025, India \\ ${ }^{\mathrm{c}}$ Department of Polymer Engineering, University of Minho, Portugal 4800-058
}

Received 4 August 2005; received in revised form 6 October 2005; accepted 7 October 2005

\begin{abstract}
Epoxy resin is chosen for our present study owing to its exceptional combination of properties such as easy processing, high safety, excellent solvent and chemical resistance, toughness, low shrinkage on cure, good electrical, mechanical and corrosion resistance with excellent adhesion to many substrates. This versatility in formulation made epoxy resins widely applied for surface coatings, adhesives, laminates, composites, potting, painting materials, encapsulant for semiconductor and insulating material for electric devices. There are numerous paint/coating systems based on epoxy resin available for corrosion and fouling prevention. They however are not completely satisfactory in field applications, where high corrosion, fouling and flame resistance are required. The demand for epoxy resin as corrosion/fouling resistant coatings is restricted mainly due to its inferior characteristics like poor impact strength, high rigidity, and moisture absorbing nature besides inadequate flame retardant properties. It is for this reason that silicones and phosphorus-based compounds are used as modifier in this work by intercrosslinking network mechanism (ICN) to obtain epoxy resin with desired properties ideally suitable for field applications for preventing corrosion and fouling with flame retardantancy. The present work involves the development of solvent free silicone/phosphorus modified epoxy coating systems, since solvent free coating systems are widely used for numerous applications due to their lower cost per unit film thickness, freedom from fire and pollution hazard and ability to provide better performance. For the development of coating systems, epoxy resin (X) serves as base material, hydroxyl terminated polydimethylsiloxane (HTPDMS) as modifier, $\gamma$-aminopropyltriethoxysilane ( $\gamma$-APS) as crosslinking agent and dibutyltindilaurate (DBTDL) as catalyst. Polyamidoamine (A), aromatic amine adducts (B) and phosphorus-containing diamine (C) were used as curing agents. The study also describes the evaluation of corrosion resistant behaviour of unmodified epoxy and siliconized epoxy coatings by potentiodynamic polarization method, electrochemical impedance spectroscopy (EIS), salt-spray and antifouling tests. The results are discussed.
\end{abstract}

(C) 2005 Elsevier B.V. All rights reserved.

Keywords: Electrochemical impedance; Capacitive behaviour; Siliconized epoxy coatings; Corrosion prevention; Antifouling; IPN coatings

\section{Introduction}

Steel is one of the major materials used for the construction of industrial structures, storage tanks, vehicles, pipelines, ships, etc. However, such structures, improperly coated with protective treatment (commercial coatings) were easily damaged by corrosion and fouling due to the environment within a month's time, resulting in direct and indirect losses to a country which could be as high as 5\% of Gross National Product. Coating is the most convenient method for preventing the corrosion/fouling of steel surfaces, storage tanks, surfaces

\footnotetext{
* Corresponding author. Tel.: +91 44 23621951; fax: +91 4428173062.

E-mail address: sri_anand_72@yahoo.com (S. Ananda Kumar).
}

of pipelines, ship bottoms and their super structures. Other methods like, use of corrosion resistant steels, metallic coatings and cathodic protection are much costlier and are used only where functional requirements make them indispensable [1].

Bio fouling is another serious economic problem to maritime activities [1-3]. Literature describes a variety of methods including immobilization of marine bacteria in hydro gels, piezoelectricity and electrolytic technologies for the control of bio fouling [4-8]. However, none of these methods is able to totally prevent fouling. The use of toxic antifouling paints has been the method of choice in many instances [3]. The use of toxic tributyl tin oxide in paints has however been banned in many countries [9-14] and it is for this reason that non-toxic alternatives are investigated in this work. 
Coating materials based on epoxy resins have gained considerable importance in many areas of technology and daily life. This is due, on the one hand, to the fact that epoxy resins can be processed relatively simply and safely and, on the other hand, to the good mechanical and chemical property level of the cured epoxy resin moulded materials. This versatility in formulation made epoxy resins widely applied industrially for surface coating, adhesive, painting materials, potting, composites, laminates, encapsulant, and insulating material for electric devices, etc. $[15,16]$.

Although numerous paint/coating systems based on epoxy resin are available for corrosion and fouling prevention, they however are not completely satisfactory in field applications, where high corrosion, fouling and flame resistance are required [17]. It is for this reason that silicones and phosphorus-based compounds are used as modifier in this work [18-20]. In particular, solvent free coatings that are the focus of this work avoid environmental health hazards. In our previous study [17], it was observed that silicone incorporation into epoxy resin enhanced the impact strength, thermal stability, moisture resistance and corrosion resistance due to its inherent flexibility, constant stress dissipating nature, partial ionic nature and excellent dielectric properties. Furthermore, the thermal stability and flame retardant properties of the siliconized epoxy resin with phosphorus diamine-curing agent were studied by the author and reported elsewhere [21]. In the present investigation, the corrosion and fouling resistance of silicone/phosphorus incorporated epoxy resin are studied by electrochemical methods and antifouling tests. Silicones are completely immiscible with epoxy resin. However, silicone modified epoxy ICN structure (Scheme 1) can be achieved successfully with a procedure reported by the author [22-25]. Further, this invention also discloses the synthe- sis of a phosphorus containing diamine-curing agent for epoxy and silicone modified epoxy resin compositions. The non-toxic products thus obtained from this invention have flame retardant properties besides antifouling and anticorrosive properties. These aspects of the work are novel.

\section{Experimental}

\subsection{Materials}

Epoxy resin GY 250 (diglycidyl ether of bisphenol A, DGEBA, with EEW 180-190, viscosity about 10,000 cP) polyamidoamine (HY 840) and aromatic amine adducts (HY 2969) were obtained from Ciba-Speciality Chemicals (India). Bis(4-aminophenyl) phenylphosphate (BAPP) was prepared by the reported procedure [26]. The hydroxyl-terminated polydimethylsiloxane (HTPDMS) used in the present study was synthesized in our laboratory from octamethylcyclotetrasiloxane by ring opening polymerization technique [22]. Dibutyltindilaurate catalyst and $\gamma$-aminopropyltriethoxysilane were obtained from Merck (Germany) and Union Carbide (USA) respectively. Phenyldichlorophosphate (PDCP) (Lancaster), p-nitrophenol (SD Fine Chemicals, India) and Copper(I) chloride (Lancaster) were used as received. Tetrahydrofuran (THF) was dried with sodium and distilled before use. Palladium on 10\% activated charcoal $(\mathrm{Pd} / \mathrm{C})$ was obtained from SD Fine Chemicals (India) and used as received.

\subsection{Surface preparation of test specimens}

Mild steel specimens cut from the same batch of sheet stock (22 gauge) of $(5 \mathrm{~cm} \times 7.5 \mathrm{~cm}) 37.5 \mathrm{~cm}^{2}$ area (with a composition

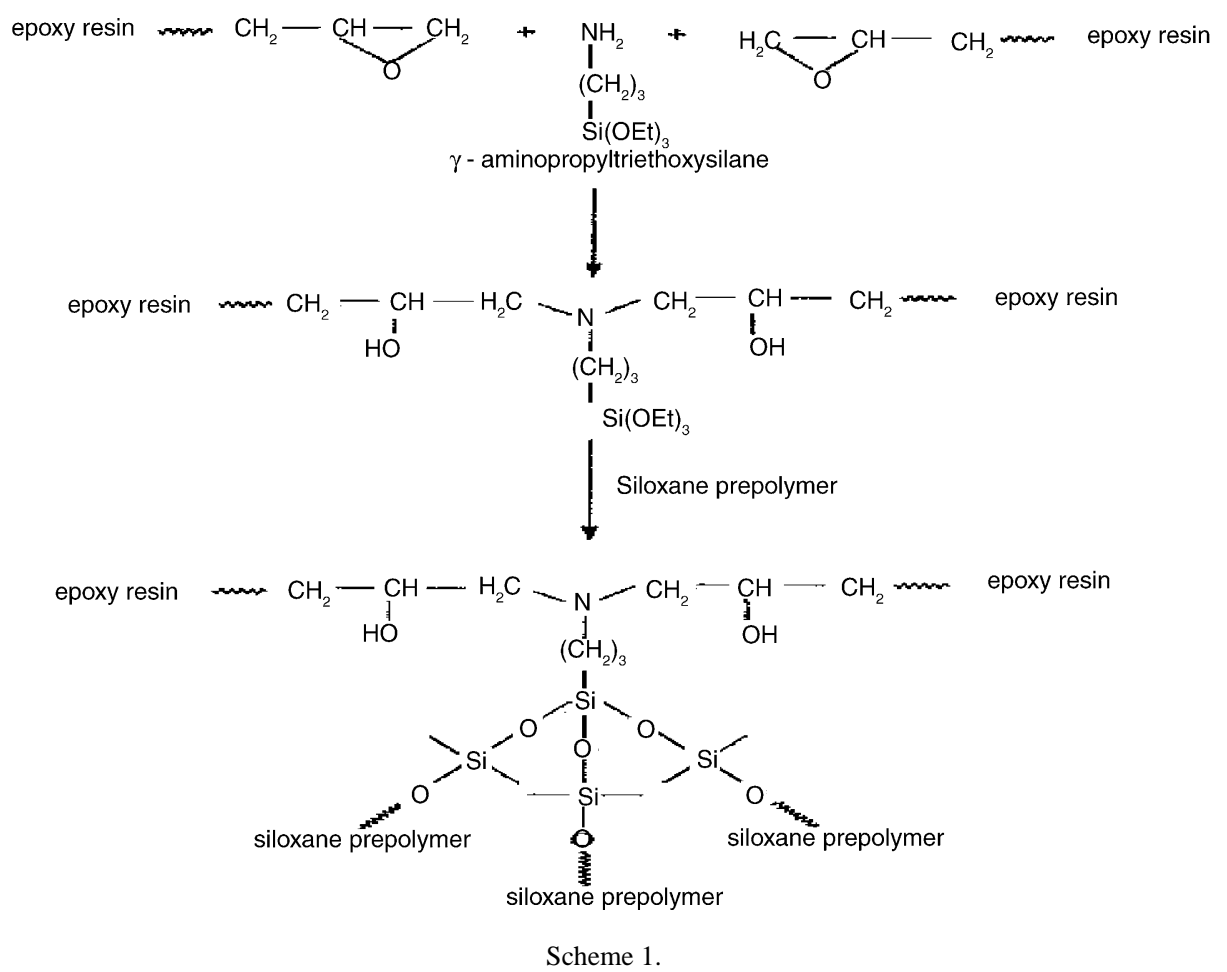


C, $0.04 \%$; Si, $0.01 \%$; Mn, 0.17\%; P, 0.002\%; S, 0.005\%; Cr, $0.04 \%$; Mo, $0.03 \% ; \mathrm{Ni}, 1.31 \%$; Fe, bal) were used as a substrate material for the present study. The specimens were degreased with acetone, and sand blasted. The test specimens were placed in the desiccator for conditioning.

\subsection{Methods}

\subsubsection{Synthesis of hydroxyl terminated} polydimethylsiloxane

HTPDMS utilized for the development of siliconized epoxy coatings was synthesized in our laboratory from octamethylcyclotetrasiloxane [22].

\subsubsection{Viscosity}

Viscosity of hydroxyl-terminated polydimethylsiloxane was determined by Brookfield digital viscometer. Molecular weight of the polymer, 14,000; refractive index, 1.3968; density, $0.956 \mathrm{~g} \mathrm{~cm}^{-3}$ and viscosity, $800-900 \mathrm{cP}$ at $25^{\circ} \mathrm{C}$.

\subsubsection{Siloxane introduction into epoxy coating system}

To obtain coating system with reasonable improvement in impact strength, moisture and corrosion resistant properties without appreciable loss of other characteristics, the tentative amount of hydroxyl terminated polydimethylsiloxane component was taken as $10 \%(\mathrm{w} / \mathrm{w})$. This has been ascertained from the data obtained from our previous study [22].

\subsubsection{Preparation of siliconized epoxy resin}

Required amount of epoxy resin, calculated percentage (w/w) of hydroxyl-terminated polydimethylsiloxane prepolymer, stoichiometric equivalent of $\gamma$-aminopropyltriethoxysilane (with respect to $\mathrm{OH}$ group of HTPDMS) and dibutyltindilaurate catalyst were thoroughly mixed at $90^{\circ} \mathrm{C}$ for $30 \mathrm{~min}$ with constant stirring. The prepolymer mix was then subjected to vacuum with the help of vacuum pump to remove the trapped air inside the blend and also to accelerate the condensation reaction (Scheme 1) between $\gamma$-aminopropyltriethoxysilane and hydroxyl terminated polydimethylsiloxane with the removal of ethanol, which formed during degassing process [21,22].

\subsubsection{Preparation of siliconized epoxy coating system}

The siliconized epoxy prepolymer mix was cured with curing agents namely polyamidoamine, aromatic amine adducts and
Table 1

Nomenclature for coating systems

\begin{tabular}{lll}
\hline Curatives & $\begin{array}{l}\text { Siloxane/epoxy } \\
0 / 100(\mathrm{w} / \mathrm{w})\end{array}$ & $\begin{array}{l}\text { Siloxane/epoxy } \\
10 / 100(\mathrm{w} / \mathrm{w})\end{array}$ \\
\hline Polyamidoamine (A) & $\mathrm{AX}_{1}$ & $\mathrm{AX}_{2}$ \\
Aromatic amine adduct (B) & $\mathrm{BX}_{1}$ & $\mathrm{BX}_{2}$ \\
Phosphorus diamine (C) & $\mathrm{CX}_{1}$ & $\mathrm{CX}_{2}$ \\
\hline
\end{tabular}

phosphorus containing diamine to get the corresponding coating systems [21,22]. The coatings were applied by bar coater as a single coat ( $200 \mu \mathrm{m}$ thick) of two-pack amine cured epoxy and siliconized epoxy resins with red iron oxide as pigment. The nomenclature of different coating systems is given in Table 1.

\subsubsection{Synthesis of phosphorus containing diamine-curing agent}

The synthesis of phosphate based amine compound was performed via reacting phenyldichlorophosphate (PDCP) with hydroxy containing chemicals [26]. The synthesis schemes are shown in Scheme 2. The phosphorus containing diamine compound bis(4-aminophenyl) phenyl phosphate (BAPP) was obtained via two-step synthesis route (Scheme 2). The dinitro bis(4-nitrophenyl) phenyl phosphate (BNPP) was initially obtained as an intermediate. The IR spectra results confirmed that pure BNPP compound was formed. BNPP was hydrogenated using $10 \% \mathrm{Pd} / \mathrm{C}$ catalyst to give the diamine compound bis(4-aminophenyl) phenyl phosphate (BAPP).

\section{Characterization techniques}

\subsection{Infrared spectra}

Infrared spectra were obtained for unmodified epoxy resin, $\gamma$-aminopropyltriethoxysilane cured epoxy resin and $\gamma$ aminopropyltriethoxysilane by Perkin Elmer 781 infrared spectrometer using $\mathrm{NaCl}$ to confirm the formation of intercrosslinking network structure (Fig. 1). Similarly the IR spectrum of BNPP and BAPP (using KBr) was also included in Figs. 2-3.

\subsection{1. ${ }^{1} H$ NMR spectrum}

${ }^{1} \mathrm{H}$ NMR Spectrum was recorded with a Bruker MSL-300 (300 MHz) NMR spectrometer using $\mathrm{CDCl}_{3}$ solvent. The ${ }^{1} \mathrm{H}$ NMR spectrum of BAPP compound is given in Fig. 4.

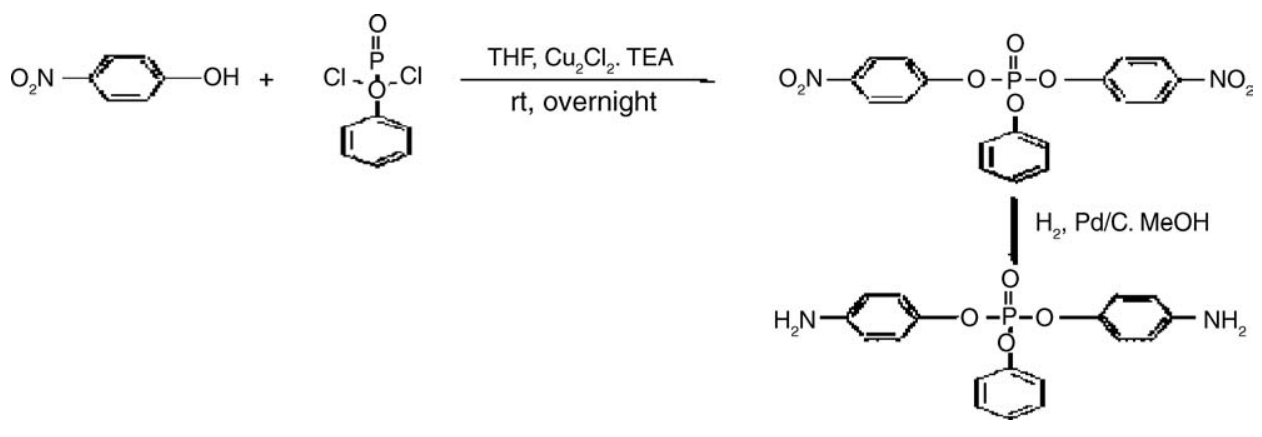




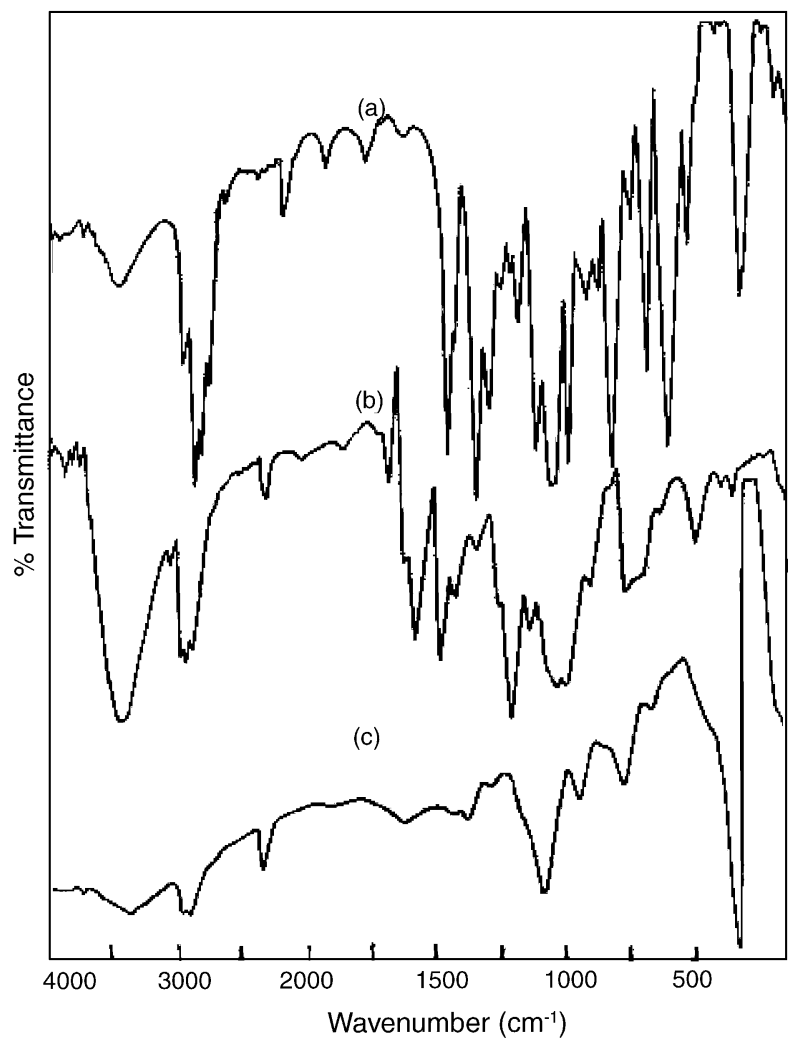

Fig. 1. Infrared spectra of epoxy (a), $\gamma$-aminopropylthiethoxysilane cured apoxy resin (b) and $\gamma$-aminopropylthiethoxysilane (c).

\subsubsection{Potentiodynmic polarization and electrochemical impedance spectroscopy}

Potentiodynmic polarization and electrochemical impedance measurements for the coated specimens were carried out with

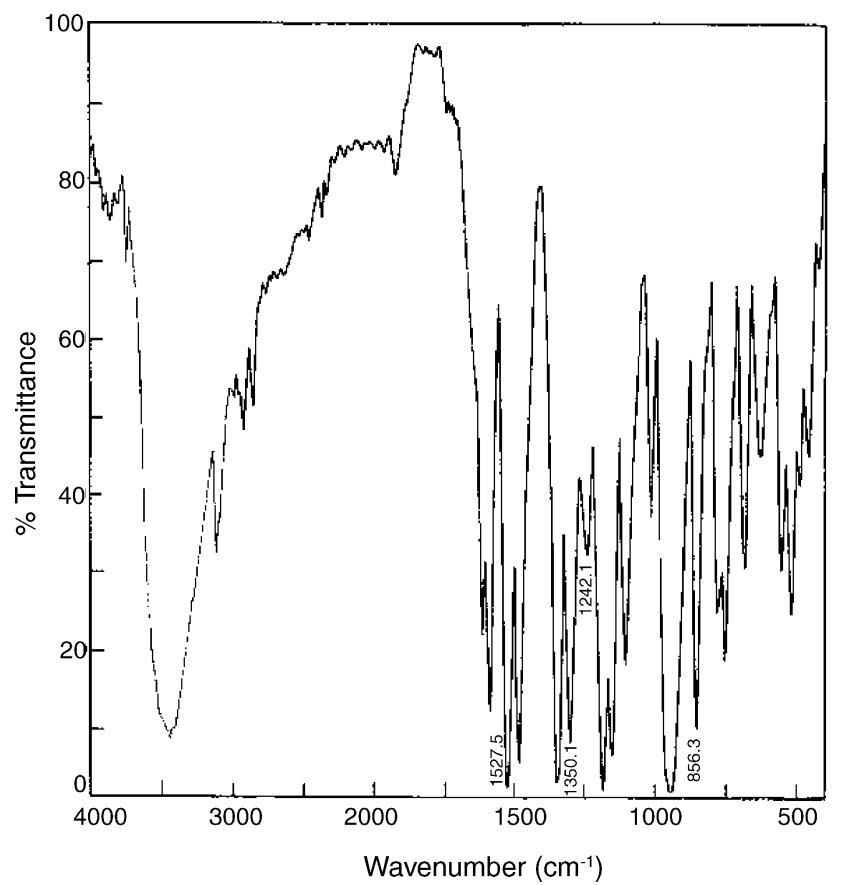

Fig. 2. IR spectrum of bis(4 nitrophenyl) phenylphosphate.

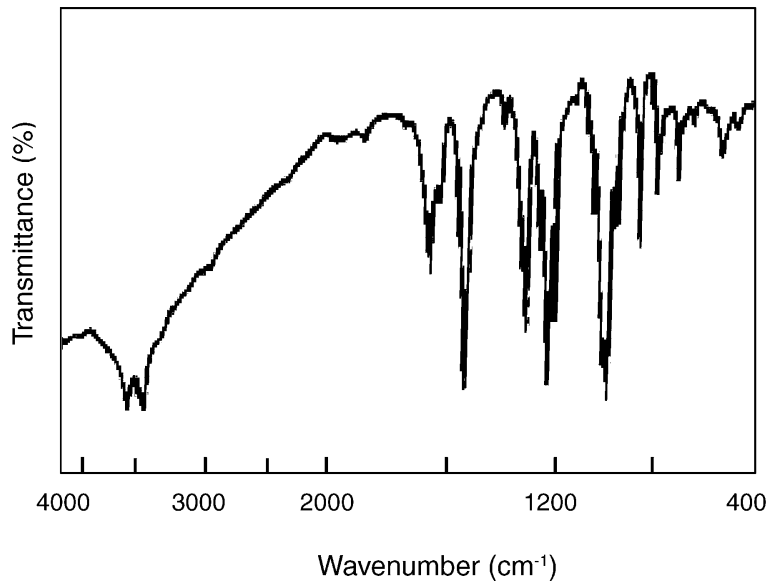

Fig. 3. IR Spectrum of BAPP.
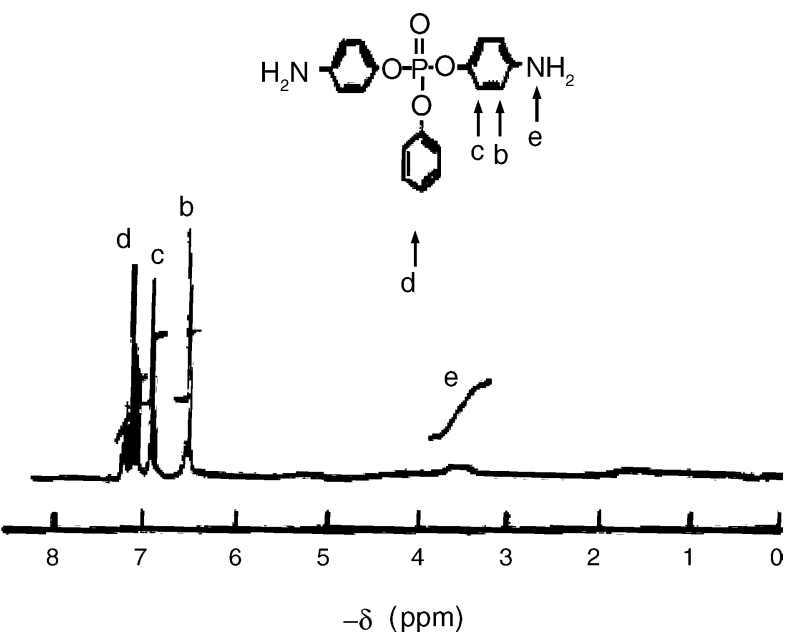

Fig. $4 .{ }^{1} \mathrm{H}$ NMR Spectrum of BAPP.

ACM instrument (Gill Ac Instrument, UK) system. The electrochemical cell used for the study consisted of the prepared coated electrode as working electrode, a platinum foil as counter electrode, saturated calomel electrode as reference electrode and 3\% sodium chloride as electrolyte medium. All measurements were carried out at the corrosion potential and the results are shown in Figs. 5-8 and the values are given in Tables 2 and 3.

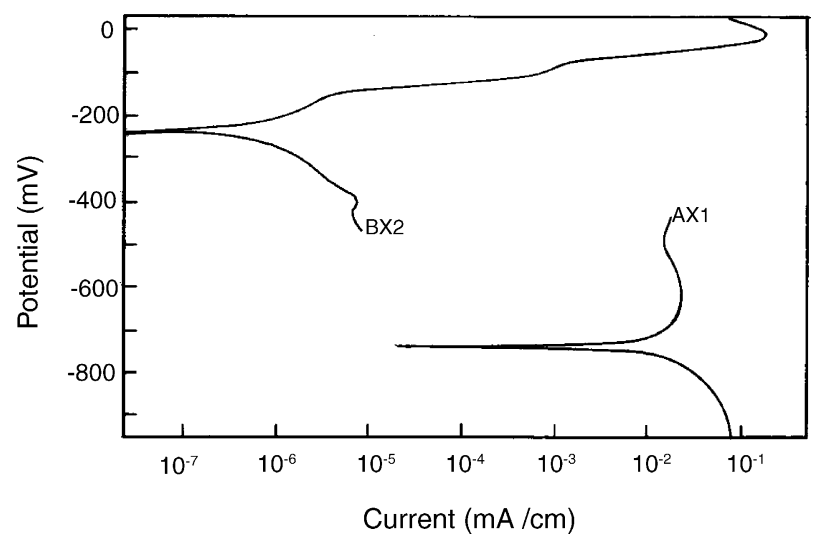

Fig. 5. Polarization response of $\mathrm{BX}_{2}$ and $\mathrm{AX}_{1}$ coating. 

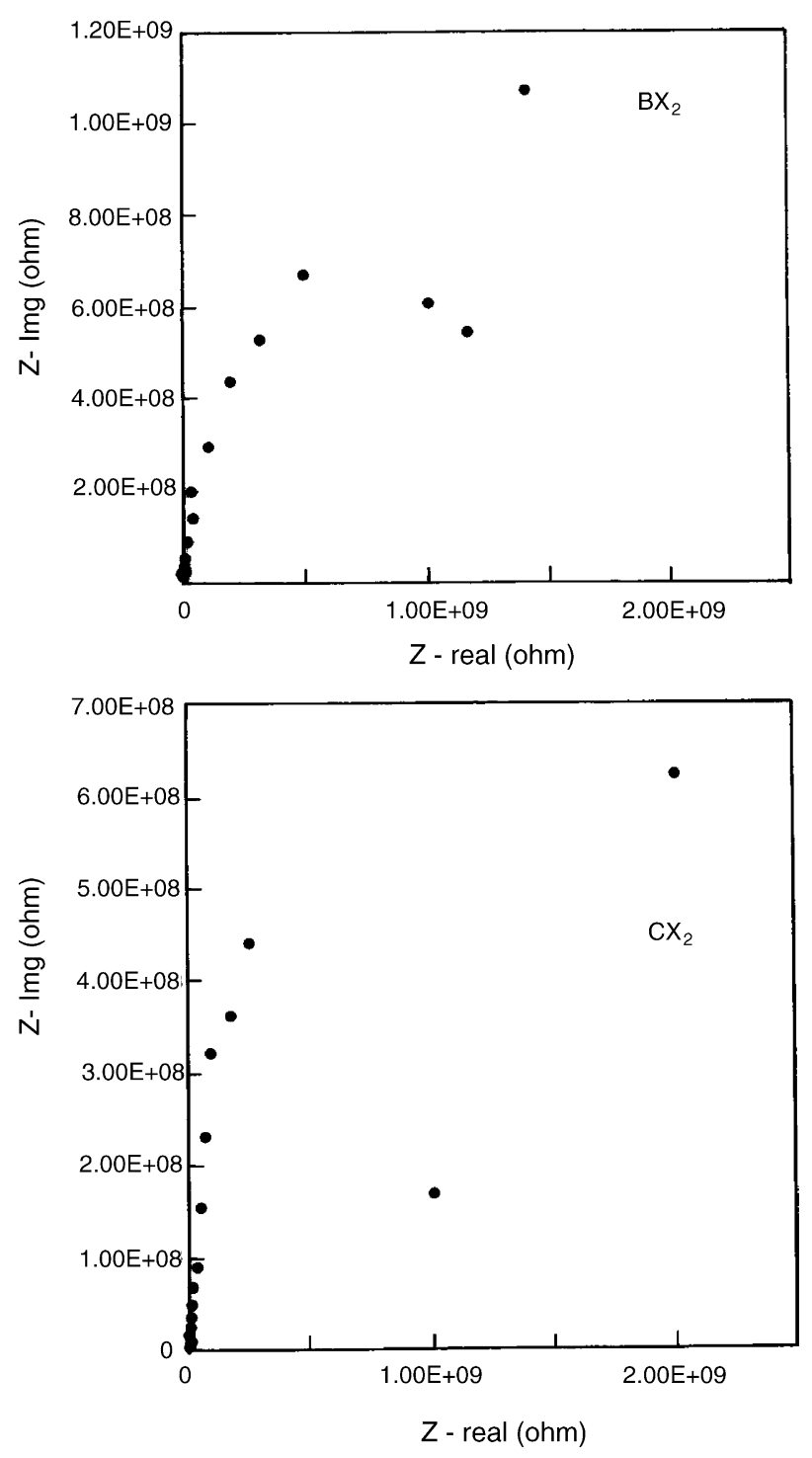

Fig. 6. Nyquist plot of coating systems.

Table 2

Polarization measurements after 90 days of immersion

\begin{tabular}{lccc}
\hline Coating systems & $E(\mathrm{mv})$ & $I_{\text {corrosion }}\left(\mathrm{nA} / \mathrm{cm}^{2}\right)$ & $\begin{array}{l}\text { Corrosion rate } \\
(\mathrm{mpy})\left(10^{-3}\right)\end{array}$ \\
\hline $\mathrm{AX}_{1}$ & -749 & 94.62 & 41.07 \\
$\mathrm{BX}_{1}$ & -460 & 50.10 & 24.91 \\
$\mathrm{CX}_{1}$ & -430 & 35.92 & 19.89 \\
$\mathrm{AX}_{2}$ & -195 & 11.20 & 4.07 \\
$\mathrm{BX}_{2}$ & -220 & 9.20 & 3.91 \\
$\mathrm{CX}_{2}$ & -141 & 9.12 & 3.87 \\
\hline
\end{tabular}

Table 3

Impedance data for siliconized epoxy coatings

\begin{tabular}{llll}
\hline $\begin{array}{l}\text { Coating } \\
\text { systems }\end{array}$ & $E(\mathrm{mv})$ & $\begin{array}{l}\text { Paint film } \\
\text { resistance }\left(R_{\mathrm{p}}\right) \\
\left(\left(\Omega \mathrm{cm}^{2}\right) \times 10^{9}\right)\end{array}$ & $\begin{array}{l}\text { Paint film } \\
\text { capacitance }\left(C_{\mathrm{c}}\right) \\
\left(\left(\mathrm{F} / \mathrm{cm}^{2-}\right) \times 10^{-10}\right)\end{array}$ \\
\hline $\mathrm{AX}_{2}$ & -195 & 0.9 & 2.2 \\
$\mathrm{BX}_{2}$ & -220 & 1.6 & 1.01 \\
$\mathrm{CX}_{2}$ & -141 & 1.1 & 1.46 \\
\hline
\end{tabular}

\subsubsection{Considerations about electrochemical impedance measurements}

Recent past, several authors investigated the failure mechanism of various coating systems by multi-frequency ac impedance measurements [27-32]. This method of monitoring the behaviour of coated surface gives valuable information about both coating degradation and the corrosion reactions occurring at the metal surface [27]. The impedance measurements were made for the specimens coated with systems (AX, BX and CX series) at a higher frequency range $(4 \mathrm{~Hz}-10 \mathrm{KHz})$ by performing the lock in experiment, followed by a fast Fourier transformed (FFT) experiment, which measures the impedance at lower frequency range $(0.1-4 \mathrm{~Hz})$. In the lock-in experiment, impedance of the coated specimens at a particular frequency was calculated by imposing a $10 \mathrm{mV}$ AC voltage, and measuring the ac current and voltage within the lock-in. For the FFT experiment, the impedance was measured from the Fourier transform of the applied potential and the measured current. The base frequency for the FFT experiment was $0.1 \mathrm{~Hz}$ and the upper limit was $4 \mathrm{~Hz}$.

\subsubsection{Salt-spray test}

Salt spray test for the coated specimens was carried out as per ASTM B117 method. The coated specimens were subjected to diagonal scratch with the help of a sharp knife in order to expose the base metal of the coated specimens to a continuous salt fog chamber containing 3\% sodium chloride solution. The test has been carried out for $1000 \mathrm{~h}$ duration at room temperature and the observations on coated panels were taken periodically. The results are shown in Figs. 9 and 10 and Table 4.

\subsubsection{Antifouling studies}

The fouling resistance of epoxy and siliconized epoxy coatings is studied by antifouling studies (Table 5). Mild steel specimens (of size $8 \mathrm{~cm} \times 5 \mathrm{~cm}$ ) coated with unmodified epoxy, siliconized epoxy coating systems with curing agents $A, B$ and $\mathrm{C}$ were used for the fouling study. The study was carried out at coast of Bay of Bengal in Chennai, on the East Coast of India. The specimens were suspended at a depth of $3 \mathrm{~m}$ from the lowest spring tide low water mark. The specimens were hung vertically using nylon ropes with proper support in a protected area for 200 days. The specimens were removed and the distribution of fouling growth was traced on a transparent sheet. This sketch was later super imposed on the specimens after the removal of fouling growth to observe the corrosion associated (induced) with fouling. The barnacles, along with other organisms, which settled on the surface of specimens coated with different coating systems, were then removed using a hard brush without damaging the specimen surface.

\section{Results and discussion}

\subsection{Spectral analysis}

The formation of siliconized epoxy network structure takes place in two steps as evidenced by IR. The first step involving the oxirane ring opening of epoxy with amino group of the $\gamma$-aminopropyltriethoxysilane, is confirmed by the 

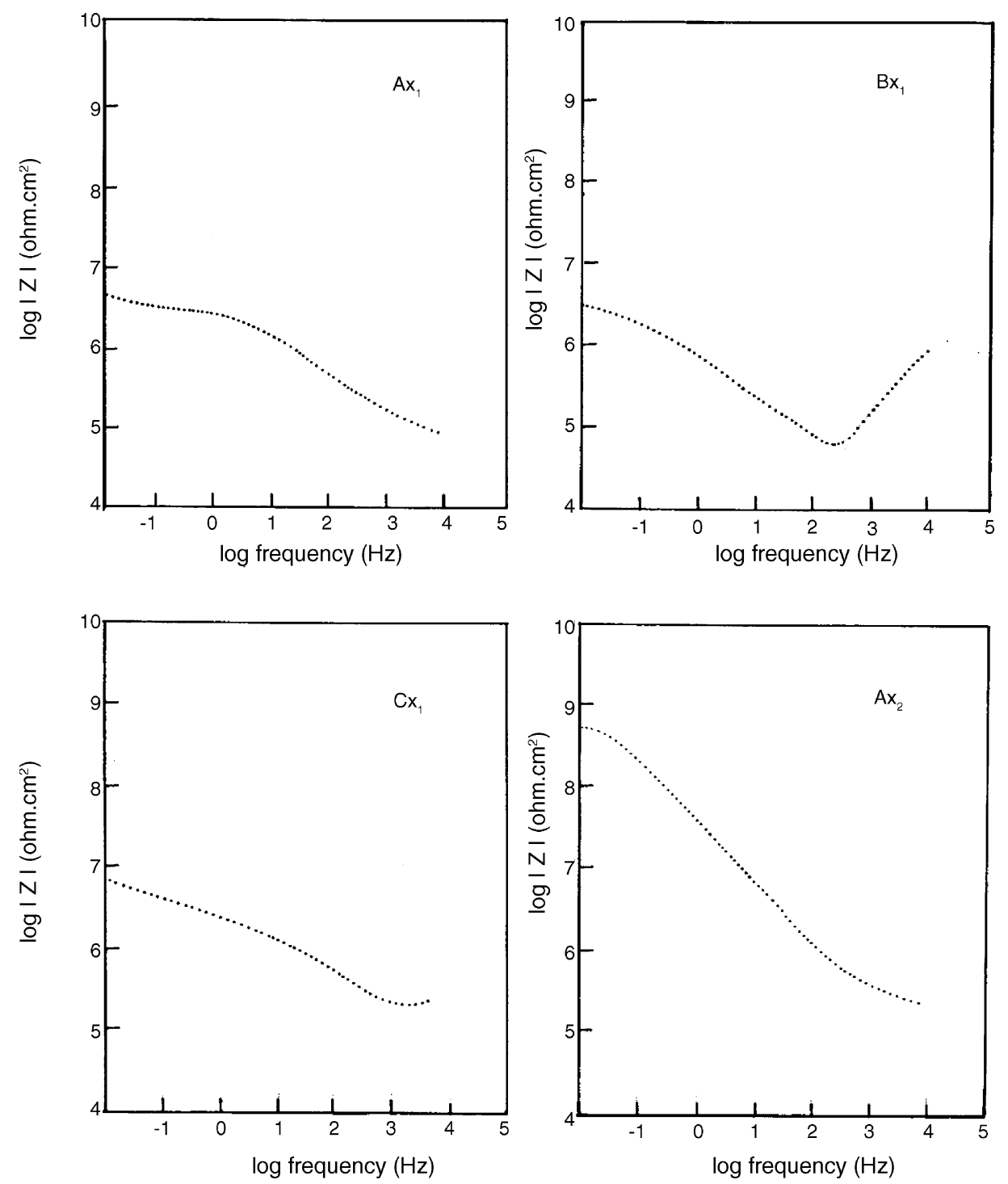

Fig. 7. Bode plots of coating systems.

disappearance of epoxy band at $913 \mathrm{~cm}^{-1}$ and appearance of hydroxyl band at $3420 \mathrm{~cm}^{-1}$. Appearance of absorption peaks at $2980 \mathrm{~cm}^{-1}$ and $2850 \mathrm{~cm}^{-1}, 1370 \mathrm{~cm}^{-1}$ confirms the presence of $-\mathrm{Si}-\mathrm{O}-\mathrm{CH}_{2} \mathrm{CH}_{3}$ and $-\mathrm{Si}-\left(\mathrm{CH}_{2}\right)_{3}-$, respectively (Fig. 1). In the second step, the alkoxy groups present in the $\gamma$-aminopropyltriethoxysilane react with hydroxyl groups of hydroxyl-terminated polydimethylsiloxane.

The IR characterization data (Fig. 2) of BNPP are as follows. IR (KBr): $856.3 \mathrm{~cm}^{-1}\left(-\mathrm{C}-\mathrm{NO}_{2}\right), 1188.1 \mathrm{~cm}^{-1}(\mathrm{Ph}-\mathrm{O}-\mathrm{Ph})$,
$1242.2 \mathrm{~cm}^{-1}(-\mathrm{P}=\mathrm{O}), 1349 \mathrm{~cm}^{-1}$ and $1529 \mathrm{~cm}^{-1}\left(\mathrm{Ph}-\mathrm{NO}_{2}\right)$ confirmed formation of BNPP compound. For BAPP compound, peaks appeared at $3513 \mathrm{~cm}^{-1}$ and $3409 \mathrm{~cm}^{-1}$ are assigned to aromatic primary amine groups. Moreover, other peaks arising from $\mathrm{P}-\mathrm{O}-\mathrm{Ph}$ at $1191 \mathrm{~cm}^{-1}$ and $\mathrm{P}=\mathrm{O}$ at $1280 \mathrm{~cm}^{-1}$ confirm (Fig. 3) that the phosphate structure is maintained after hydrogenation. Furthermore, ${ }^{1} \mathrm{H}$ NMR Spectrum characterized BAPP compound (Fig. 4). The absorption of amine protons is found at $\delta=3.45 \mathrm{ppm}$. Peaks at $\delta=6.52-6.94 \mathrm{ppm}$

Table 4

Data resulted from salt-spray and immersion studies

\begin{tabular}{llc}
\hline Coating systems & Salt-spray test for $1000 \mathrm{~h}$ & Immersion test for 90 days \\
\hline $\mathrm{AX}_{1}$ & Rust at scratch small blisters & Blisters all over and rusted \\
$\mathrm{BX}_{1}$ & Rust at scratch small blisters & Small blisters and rusted \\
$\mathrm{CX}_{1}$ & Rust at scratch small blisters & Small blisters and rusted \\
$\mathrm{AX}_{2}$ & No blisters, rust did not spread through scratch. Bright surface after removal of coating & No blisters bright surface \\
$\mathrm{BX}_{2}$ & No blisters, rust did not spread through scratch. Bright surface after removal of coating & No blisters bright surface \\
$\mathrm{CX}_{2}$ & No blisters, rust did not spread through scratch. Bright surface after removal of coating & No blisters bright surface
\end{tabular}



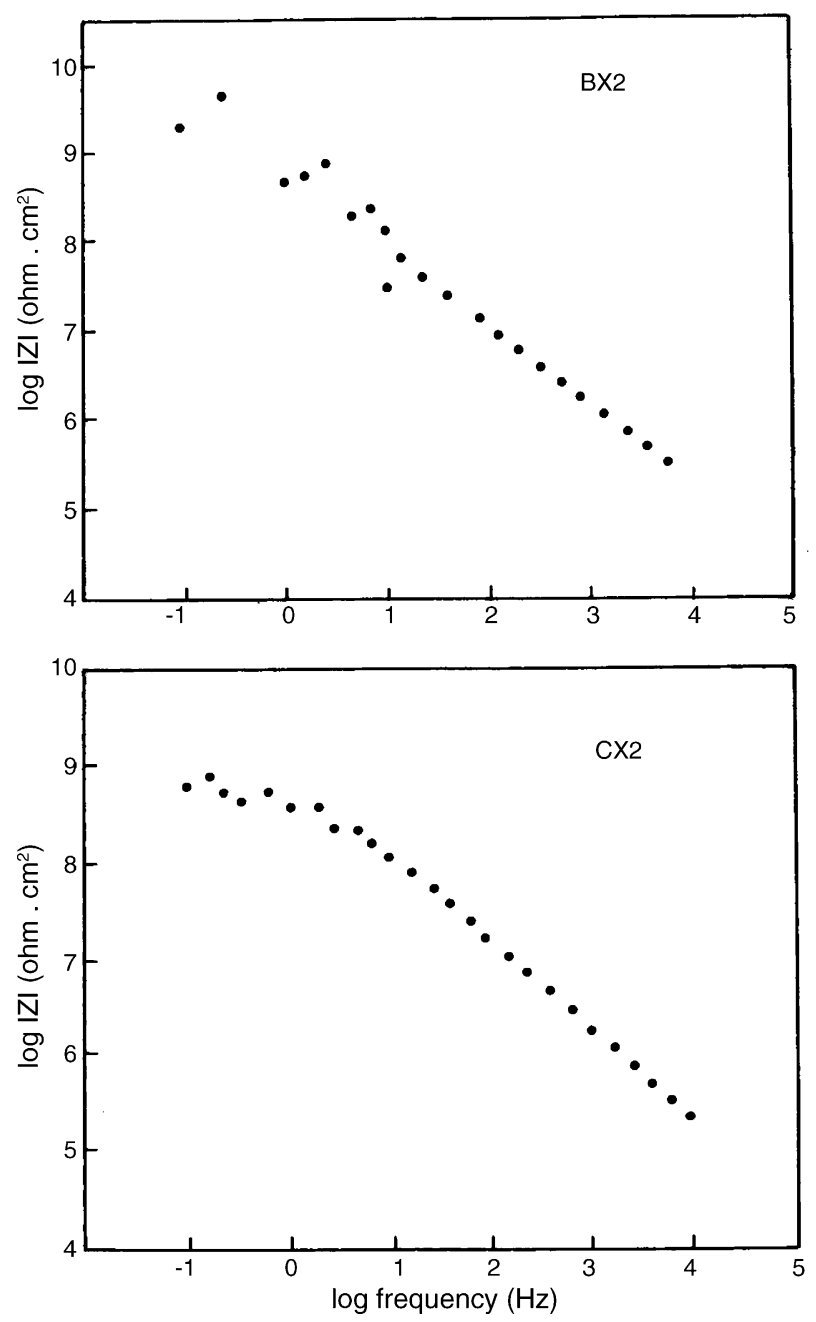

Fig. 8. Bode plots of coating systems.

$\left(\mathrm{C}_{6} \mathrm{H}_{4}-\mathrm{NH}_{2}\right)$ and $\delta=7.09-7.43 \mathrm{ppm}\left(\mathrm{P}-\mathrm{O}-\mathrm{C}_{6} \mathrm{H}_{5}\right)$ are also found.

\subsubsection{Results of potentiodynamic polarization study}

The polarization response of the coated specimens was not steady at the initial stage (after 30 days of immersion in $3 \%$ $\mathrm{NaCl}$ ) owing to the high resistance offered by the coatings. However, the polarization study was performed for specimens after 60 days of immersion in $3 \%$ sodium chloride solution. The polarization response is shown in Fig. 5 and the polarization

Table 5

Data resulted from fouling study

\begin{tabular}{lllll}
\hline \multicolumn{5}{c}{ Mortality of barnacles $(\%)$} \\
\cline { 2 - 5 } & Total & $>8 \mathrm{~mm}$ & $5-8 \mathrm{~mm}$ & $4 \mathrm{~mm}$ \\
\hline Uncoated & 70 & 10 & 40 & 47 \\
$\mathrm{AX}_{1}$ & 40 & - & 30 & 40 \\
$\mathrm{BX}_{1}$ & 25 & - & 15 & 20 \\
$\mathrm{CX}_{1}$ & 30 & - & 15 & 20 \\
$\mathrm{AX}_{2}$ & 20 & - & 10 & 12 \\
$\mathrm{BX}_{2}$ & 15 & - & 10 & 10 \\
$\mathrm{CX}_{2}$ & 10 & - & 10 & 12 \\
\hline
\end{tabular}

values are given in Table 2. It was observed from the figure that, the polarization response of the $\mathrm{AX}_{2}, \mathrm{BX}_{2}$ and $\mathrm{CX}_{2}$ systems was towards anodic side (Fig. 5) as the time of immersion progressed. In contrast to this observation, the other systems namely $\mathrm{AX}_{1}, \mathrm{BX}_{1}$ and $\mathrm{CX}_{1}$ showed a response towards cathodic side. The shift of polarization response towards anodic side for $\mathrm{AX}_{2}$, $\mathrm{BX}_{2}$ and $\mathrm{CX}_{2}$ coating systems may be attributed to the inherent hydrophobic nature of silicone which offers high corrosion resistance and low values of corrosion current. As a consequence, siliconized epoxy coating systems, irrespective of the curing agents employed have the ability to withstand against severe corrosive environment for a longer duration. The shift of polarization response towards cathodic side for $\mathrm{AX}_{1}, \mathrm{BX}_{1}$ and $\mathrm{CX}_{1}$ systems may be due to the slight moisture absorbing nature of epoxy resin, which reflects their poor corrosion protection compared to that of siliconized epoxy coatings. The corrosion potential and open circuit potential of all coating systems behave in a similar manner after 90 days of duration. The corrosion current measured for all siliconized coatings was found to be very low (in $\mathrm{nA} / \mathrm{cm}^{2}$ ), which is a substantial evidence that these coatings have very high corrosion resistance than epoxy coatings due to their excellent adhesion on steel and high water resistance as well.

\subsubsection{Results of impedance study}

The Nyquist and Bode plots for epoxy and siliconized epoxy coating systems obtained after 90 days of immersion in 3\% sodium chloride solution at their respective open circuit potential are illustrated in Figs. 6-8, respectively. It can be seen that, all coating systems exhibit an incomplete semicircle (Fig. 6) in the high frequency region, followed by a low frequency diffusion tail known as Warburg diffusion tail [30,31]. The formation of an incomplete semicircle suggests that the sodium chloride solution has just started permeating through the coating systems. The formation of a low frequency diffusion tail in all coating systems confirms that the corrosion process is a diffusion-controlled reaction [32]. Based on the observations made for all coating systems, an equivalent electrical circuit model is proposed to explain the corrosion behaviour of these coatings in 3\% sodium chloride solution (Fig. 11). This model assumes that corrosion of the coated metal occurs by the same mechanism, which normally occurs on the bare metal, but with a greatly reduced active surface area. Many investigators have employed this model for evaluating the corrosion resistant behaviour of various coating systems [27]. The capacitance $\left(C_{\mathrm{c}}\right)$ and resistance $\left(R_{\mathrm{p}}\right)$ values of coating systems were calculated from them corresponding Nyquist plots and are presented in Table 3. The resistance values of the coatings were calculated from the corresponding Nyquist plots and the capacitance values were calculated using the equation given below.

$C=\frac{1}{2} \prod f_{\max } R_{\mathrm{p}}$

where $f_{\max }$ is the frequency in $\mathrm{Hz}$ at the maximum point of the semicircle and $R_{\mathrm{p}}$ is the paint film resistance in $\Omega \mathrm{cm}^{2}$. A paint film resistance of $10^{6} \Omega \mathrm{cm}^{2}$ is generally viewed as being indicative of a good coating [24]. The resistance and the capac- 


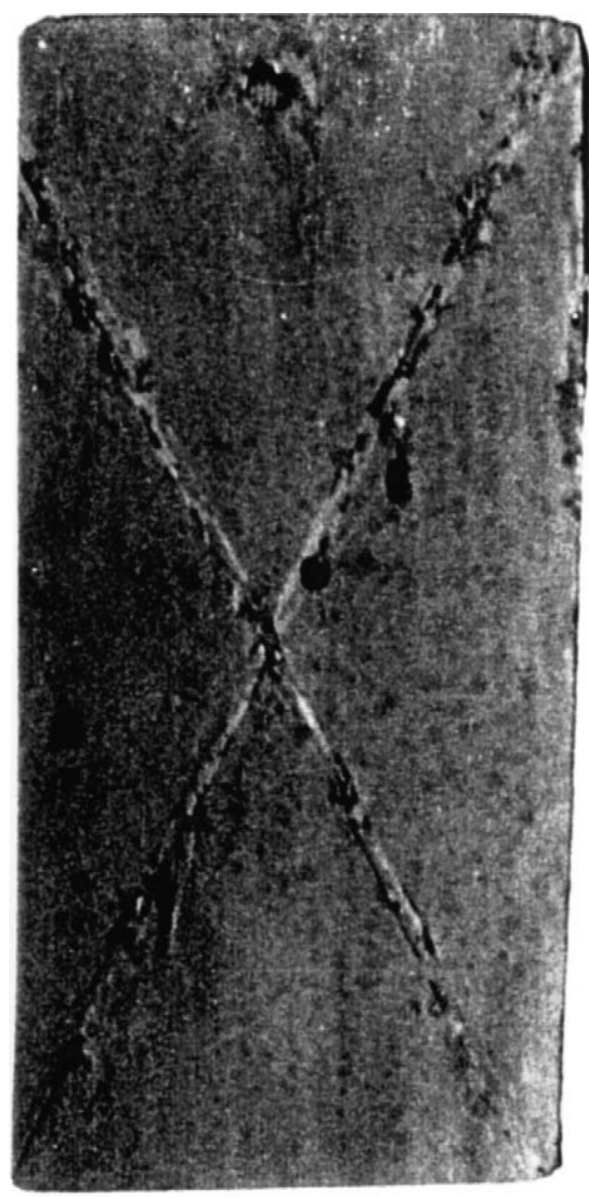

$\mathrm{AX}_{1}$

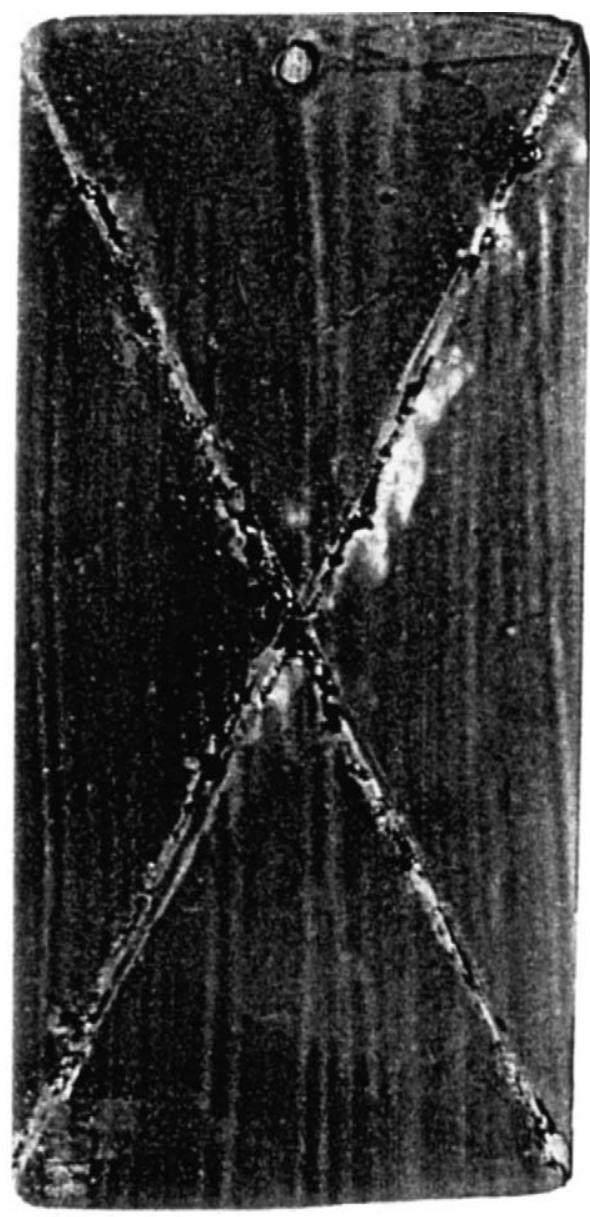

$\mathrm{BX}_{1}$

Fig. 9. Salt spray test result for $\mathrm{AX}_{1}$ and $\mathrm{BX}_{1}$ coating systems.

itance values of siliconized epoxy coating systems $\left(\mathrm{AX}_{2}, \mathrm{BX}_{2}\right.$ and $\mathrm{CX}_{2}$ ) of the present study are in the range of $10^{9} \Omega \mathrm{cm}^{2}$ and $10^{-10} \mathrm{~F}$, respectively. The capacitance values associated with the high frequency semicircle are much lower than typical double layer capacitance values and therefore cannot be due to corrosion reactions at the substrate/coating interface. These values are comparable to the values reported elsewhere for conventional polymeric coatings [24]. On this basis, the high frequency semicircle in the Nyquist plots (Fig. 6) can be attributed to the siliconized epoxy coating systems. The high values of resistance in the order of $10^{9} \Omega \mathrm{cm}^{2}$ obtained from Bode plots (Figs. 7 and 8) confirm that there was no contact between the electrolyte and metal substrate and suggest that the siliconized epoxy coating systems $\left(\mathrm{AX}_{2}, \mathrm{BX}_{2}\right.$ and $\left.\mathrm{CX}_{2}\right)$ exhibit superior corrosion protection to steel surfaces than unmodified epoxy coating systems $\left(\mathrm{AX}_{1}, \mathrm{BX}_{1}\right.$ and $\left.\mathrm{CX}_{1}\right)$. The excellent corrosion resistance offered by the coating systems $\left(\mathrm{AX}_{2}, \mathrm{BX}_{2}\right.$ and $\mathrm{CX}_{2}$ ), may be explained due to the inherent hydrophobic nature of alkyl pendant groups present in silicone moiety that gives coating films with excellent adhesion, high resistance to chemicals, solvents, electrolytes and inorganic acids, under varying environmental conditions [24,25,33]. However, the extent of the permeation of electrolyte and their corrosion resistant behaviour vary according to the nature of coatings and their bonding characteristics [24]. For example, among the coating systems studied, aromatic amine (DDM) and phosphorus containing diamine (BAPP) cured siliconized epoxy coatings have higher corrosion resistance (Tables 2 and 3) than polyamidoamine cured one. This minimum corrosion resistance offered by polyamidoamine-cured system may be explained due to the formation of intermolecular hydrogen bond, which is influenced by polar amide group of polyamidoamine curative [17]. The high corrosion resistance offered by aromatic amine systems may be attributed to the formation of intercrosslinking network structure and their rigid nature.

\subsubsection{Salt-spray test results}

The $1000 \mathrm{~h}$ salt-spray test supports the results obtained from EIS studies. The results are shown in Figs. 9 and 10 and Table 4. At the end of the salt-spray test, no visible corrosion products were seen on the surface of the unscratched area of the coated specimens. Corrosion products were seen mainly on scratched area of the coated specimens. Furthermore, the spreading of corrosion underneath the coating film is lower in the case of siliconized epoxy $\left(\mathrm{AX}_{2}, \mathrm{BX}_{2}\right.$ and $\left.\mathrm{CX}_{2}\right)$ coated specimens than in their epoxy counter parts $\left(\mathrm{AX}_{1}, \mathrm{BX}_{1}\right.$ and $\left.\mathrm{CX}_{1}\right)$. It is also evident 


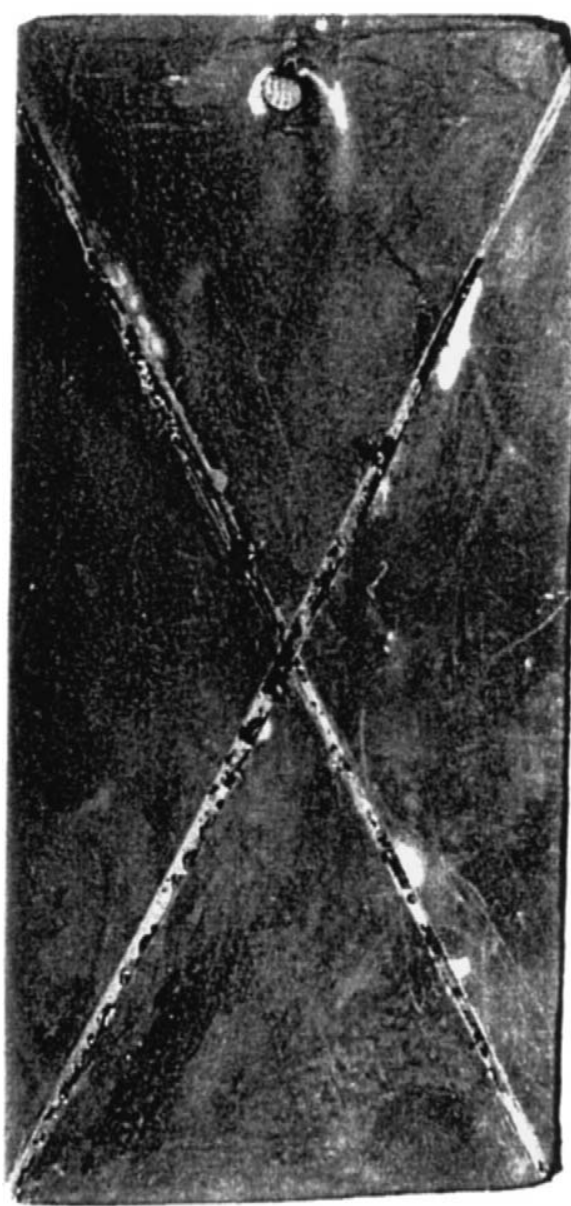

$\mathrm{AX}$

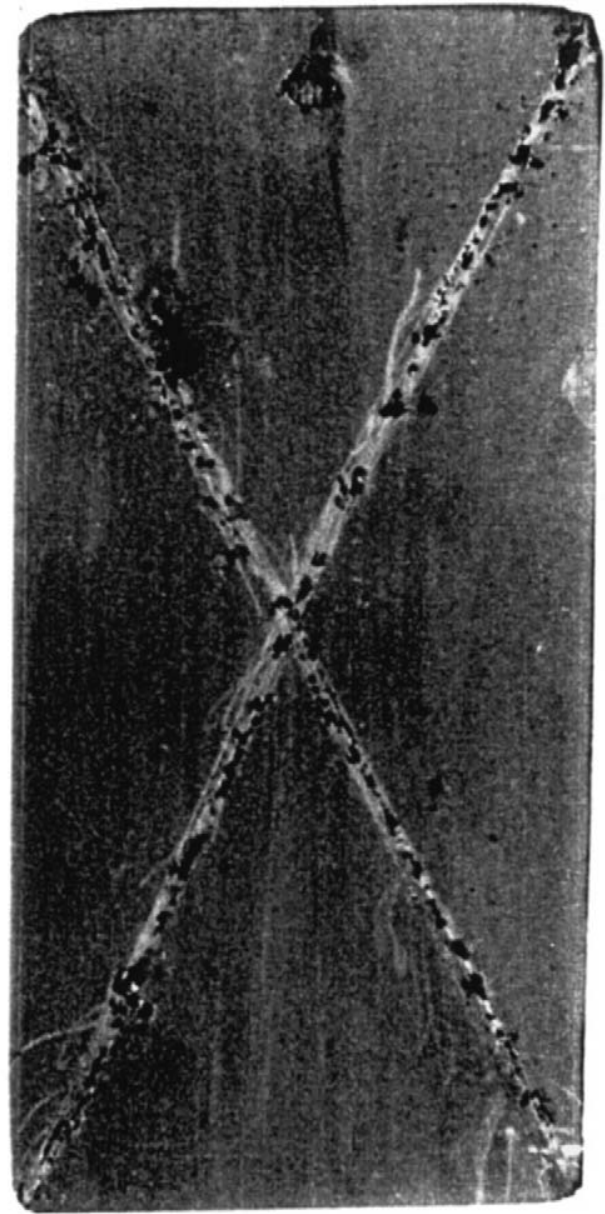

$\mathrm{BX}$,

Fig. 10. Salt spray test result for $\mathrm{AX}_{2}$ and $\mathrm{BX}_{2}$ coating systems.

from the Table 4 that siliconized epoxy coated specimens show excellent corrosion resistance in salt-spray test. It was interesting to note that, siliconized epoxy coated specimens looked bright after removing the coating. The superior corrosion resistance offered by coating systems $\mathrm{AX}_{2}, \mathrm{BX}_{2}$ and $\mathrm{CX}_{2}$ may be explained due to the inherent water repelling nature of silicone, which

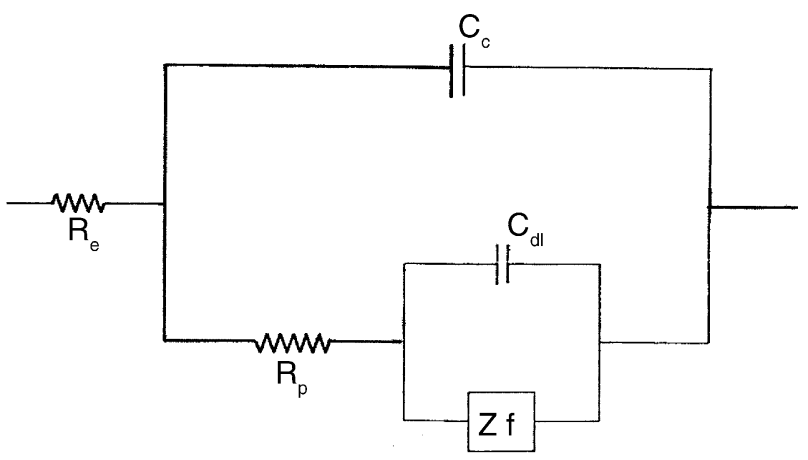

Fig. 11. Equivalent electrical circuit model. $C_{\mathrm{c}}$ is the capacitance of the intact coating layers; $R_{\mathrm{e}}$, electrolytic resistance; $R_{\mathrm{p}}$, resistance of the electrolyte in the pores; $C_{\mathrm{dl}}$, double layers capacitance at the base of the pores; $Z_{\mathrm{f}}$, Faradic impedance of the corrosion reaction at the base of the pores. reduces the transit of corrosive species into the metal surface by forming a protective layer with its surface active properties [25].

\subsubsection{Results from antifouling studies}

Barnacles of the species 'Balanus Variegatus' were invariably found to be the dominant one during the study, and they showed a maximum growth of $8 \mathrm{~mm}$ in diameter over uncoated mild steel specimens after 30 days of immersion. There was no fouling noticed in the case of mild steel specimens coated with unmodified epoxy and siliconized epoxy systems even after the end of 30 days of immersion. Apart from barnacles, which were always the primary settlers, other foulants like mussels, tube worms and hydroids were also found on the specimens; however, at the end of 100 days there was a fouling growth noticed mainly due to barnacles, mussels, tubeworms and hydroids. The fouling growth on the test specimens varies accordingly to the nature of coating composition (Table 5). However, the variation of fouling growth is not appreciable.

At the end of 200 days of test period, it was noticed that about $70 \%$ of the barnacles on uncoated specimens was dead. Of the dead barnacles $50 \%$ were $4 \mathrm{~mm}$ in size, $40 \%$ were $5-8 \mathrm{~mm}$ in 
size and rest were below $4 \mathrm{~mm}$ in size. Similarly, in the case of specimens coated with siliconized epoxy $\left(\mathrm{CX}_{2}\right)$ about $10 \%$ of the barnacles were dead. Of the dead, $10 \%$ of them were in between 5 and $8 \mathrm{~mm}$ in size, $12 \%$ of them were about $4 \mathrm{~mm}$ in size. The fouling growth of barnacles and other organisms on coated steel specimens vary according to the nature of coating and its composition. It was also noticed that dead barnacles over uncoated steel and coated steel specimens induce pitting and crevice corrosion. However, almost all dead barnacles of size $5-8 \mathrm{~mm}$ and more were the potential contributors for the pitting corrosion, whereas barnacles below $4 \mathrm{~mm}$ in size did not contribute significantly to pitting corrosion.

Siliconization of epoxy resin repels barnacle adherence on coated steel substrate when compared to that of unmodified epoxy and apparently retards corrosion associated fouling. In the present study, uncoated steel specimens showed the maximum number of dead barnacles. However, the data resulted from bare steel test specimens reveal that unstable substrate (surface) conditions could also be an important factor influencing the growth and survival of barnacles. The relatively high rate of corrosion of uncoated mild steel specimens and resultant corrosion products provide an unstable substratum to settle barnacle cyprus and other organisms. In addition, as the barnacles grow and subsequently dropped off the surface of the uncoated steel specimens.

Some of the coated specimens $\left(\mathrm{AX}_{2}, \mathrm{BX}_{2}\right.$ and $\left.\mathrm{CX}_{2}\right)$ did not even show any appreciable corrosion beneath the barnacles. This may be due to the obstruction of oxygen diffusion beneath the barnacle shell caused by their direct adhesion on the metal surface. Further, metabolic products, products of decay, and growth of sulphate reducing bacteria provide acidic conditions inside the shell facilitating the initiation of pits [32].

It was noticed that, the formation of pits was at the centre portion of the substrate and this could possibly be due to the ease of diffusion of metabolic products as well as due to the possibility of growth of sulphate reducing bacteria at the centre. In the case of edges of test specimen, especially if two barnacles were adjacent, crevice corrosion was observed rather than pitting. These observations support the theory of differential aeration between two neighbouring barnacles and the metal surface often used to explain the corrosion phenomenon [32]. Presumably, beneath the case of the dead barnacles, corrosion may have proceeded from the pit to the edges and not vice versa. It was observed that in the case of a few live barnacles, corrosion spreads from the edges to the centre.

From the study, it is observed that corrosion occurs due to adherence of barnacles of varying sizes on steel specimens. Further, it is also noticed that, specimens coated with siliconized epoxy resin offer maximum protection against fouling caused by marine organisms. The number of dead barnacles attached on siliconized epoxy coated specimens is lower than those of specimens coated with unmodified epoxy coatings. This suggests that siliconization of epoxy resin improves the corrosion and fouling resistance of steel surface. Silicone modification with epoxy prevents the marine organisms to settle over the surface of the specimen due to its $-\mathrm{Si}-\mathrm{O}-\mathrm{Si}-$ skeleton and partial ionic character which always resist microbial and other organisms by its surface-active properties besides its inherent molecular structure [34]. Among the systems, phosphorus diamine and aromatic amine cured siliconized epoxy coated specimens showed excellent corrosion and fouling resistance owing to their superior chemical resistance and rigid aromatic structure.

\section{Conclusion}

Coatings employed for field applications require high corrosion, fouling and flame resistant properties. It is for this reason that solvent free silicone/phosphorus modified epoxy coating systems are developed due to their lower cost per unit film thickness, freedom from fire and pollution hazard and ability to provide better performance. Silicone and phosphorus-based compounds are used as modifier for epoxy resin in this work by intercrosslinking network mechanism (ICN) to make epoxy resin ideally suitable for high performance coating applications to prevent corrosion and fouling with flame retardant properties. The corrosion and fouling resistant behaviour of unmodified epoxy and siliconized epoxy coatings are evaluated by potentiodynamic polarization method, electrochemical impedance spectroscopy (EIS), salt-spray and antifouling tests. Siliconized epoxy coatings exhibit very low corrosion current (in $\mathrm{nA} / \mathrm{cm}^{2}$ ) and high paint film resistance in the order of $10^{9} \Omega \mathrm{cm}^{2}$, which is substantial evidence for their very high corrosion resistance compared to epoxy coatings. The $1000 \mathrm{~h}$ salt-spray test supports the results obtained from EIS studies. At the end of the salt-spray test, no visible corrosion products were seen on the surface of the unscratched area of the coated specimens. The spreading of corrosion underneath the coating film is very low in the case of siliconized epoxy coated specimens compared to their epoxy counter parts. Furthermore, siliconization of epoxy resin repels barnacle adherence on coated steel substrate when compared to that of unmodified epoxy and apparently retards corrosion associated fouling. From the study, it can be concluded that the silicone/phosphorus modified epoxy coatings prevent the adherence and settling of marine organisms on steel structures and improve their corrosion resistance. These coatings are determined to have extensive application in marine industry to improve the longevity of marine structures when compared with other conventional coating systems.

\section{Acknowledgments}

One of the authors S. Ananda Kumar is grateful to CSIR and FCT, Portugal for providing financial assistance to carryout this work. The authors are thankful to Dr S. Srikanth (Scientistin-Charge), Dr T.S.N. Sankaranarayanan (Scientist) and Selvi Krishnaveni (Research Scholar), National Metallurgical Laboratory, Madras Centre for their help in carrying out impedance test for samples.

\section{References}

[1] F.L. Laque, Marine Corrosion: Causes and Prevention Corrosion Monograph Series, John Wiley \& Sons, New York, 1975.

[2] J.R. Lewis, A.D. Mercer, Corrosion and Marine Growth of Offshore Structures, Ellis Horwood Ltd, Chichester, 1984. 
[3] V.J.D. Rascio, C.A. Giudice, B. Delamo, Corros. Rev. 8 (1/2) (1988) 87.

[4] A.S. Clarke, New Sci. 18 (1995) 38

[5] K.V.K. Nair, J. Indian Inst. Sci. 79 (1999) 497.

[6] P. Gatenholm, S. Kjellberg, J.S. Marita, Proceedings of the ACS Division of Polymeric Materials Science and Engineering, vol. 66, ACS, Washington, DC, 1992, p. 490.

[7] M. Usani, K. Tomoshige, H. marita, Proceedings of the International Offshore and Polar Engineering Conference, vol. 4, ISOPE, Golden, CO, USA, 1994, p. 644.

[8] M. Rahmoune, M. Latour, J. Intelligent Mater. Syst. Struct. 7 (1) (1996) 33.

[9] M. Rahmoune, M. Latour, Smart Mater. Struct. 4 (3) (1995) 195.

[10] R. Dalley, Biofouling 1 (1989) 363.

[11] R.J. Maguire, Water Sci. Technol. 25 (11) (1992) 125.

[12] K.B. Van Slooten, J. Tarradellas, Environ. Toxicol. Chem. 13 (5) (1994) 755.

[13] D. Shugui, H. Guolan, C. Yong, Water Pollut. Res. J. Can. 30 (1) (1995) 33.

[14] J.W. Tas, A. Keizer, A. Opperhuizen, Bull. Environ. Contam. Toxicol. 57 (1) (1996) 146.

[15] C.S. Wang, J.Y. Shieh, Eur. Polym. J. 36 (2000) 443.

[16] C.H. Lin, C.S. Wang, Polymer 42 (2001) 1869.

[17] S. Ananda Kumar, M. Alagar, Eur. Coat. J. 4 (2001) 152.

[18] G.H. Hsiue, Y.L. Liu, J. Tsiao, J. Appl. Polym. Sci. 78 (2000) 1.
[19] G.H. Hsiue, Y.L. Liu, H.H. Liao, J. Polym. Sci., Part A: Polym. Chem. 39 (2001) 986.

[20] M. Banks, J.R. Ebdon, M. Johnson, Polymer 35 (1994) 3470.

[21] S. Ananda Kumar, J. Jayashanker, Z. Denchev, M. Alagr, Polym. Adv. Technol. (2005) (communicated).

[22] S. Ananda Kumar, T.S.N. Sankaranarayanan, Prog. Org. Coat. 45 (4) (2002) 323.

[23] S. Ananda Kumar, M. Alagar, Eur. Coat. J. 5 (2002) 39.

[24] S. Ananda Kumar, M. Alagar, V. Mohan, J. Mater. Eng. Perform. ASM International Publication, USA, 11(2) (2001) 123.

[25] S. Ananda Kumar, M. Alagar, V. Mohan, Eur. Coat. J. 5 (1999) 45.

[26] Y.L. Liu, G.H. Hsiue, Y.S. Chu, J. Polym. Sci. A: Polym. Chem. 5 (1997) 565.

[27] I. Sekine, Prog. Org. Coat. 31 (1997) 73.

[28] F. Mansfeld, M. Kendig, Electrochemical Impedance Tests for Protective Coatings, ASTM STP 866, p. 122.

[29] E.M. Pearce, R. Liepins, Environ. Health Perspect. 11 (1975) 69.

[30] J.N. Murray, Prog. Org. Coat. 30 (1997) 225.

[31] J. Scully, Electrochemical Methods for Laboratory Corrosion Testing in Corrosion and Evaluation, ASTM STP 1000, Philadelphia, p. 351.

[32] F. Lugi, F. Franca, Corros. Prevent. Control, 86, 146.

[33] H. Lee, K. Neville, Handbook of Epoxy Resins, McGraw Hill Co, New York, 1967.

[34] W. Noll, Chemistry and Technology of Silicones, Academic Press, New York, 1967. 